\title{
Reflexões sobre o uso da Tecnologia Digital da Informação e Comunicação na Formação do Licenciando de Ciências
}

\author{
Luciana de Lima ${ }^{1,2}$, Júlio Wilson Ribeiro², Mário Jorge Nunes Costa ${ }^{2}$, Robson \\ Carlos Loureiro ${ }^{1}$ \\ ${ }^{1}$ Instituto UFC Virtual - Universidade Federal do Ceará (UFC) \\ Av. Humberto Monte, s/n - 60.440-554 - Fortaleza - CE - Brazil \\ ${ }^{2}$ Programa de Pós-Graduação em Educação - Universidade Federal do Ceará (UFC) \\ Rua Waldery Uchoa, 01 - 60020-110 - Fortaleza - CE - Brazil \\ luciana@virtual.ufc.br, julioweuol.com.br, robsonevirtual.ufc.br, \\ costajorgemeyahoo.com.br
}

\begin{abstract}
The objective is to analyze the relationships between prior knowledge and the proposed licensing student actions in the area of Science related to the pedagogical use of TDIC at the school. The research has been done with Biology and Physics students of the semester 2011.2, It was characterized as a Case Study and divided into the following stages: prior knowledge, lesson planning and analysis. It uses quizzes and lesson plans as digital data sources. It was found that undergraduates have an applicationist vision of TDIC use in science lessons, with the possibility of change in the cases that arise for the construction of knowledge from the reflection.
\end{abstract}

Resumo. Busca-se analisar as relações estabelecidas entre os conhecimentos prévios e as propostas de ação pedagógica de licenciandos na área de Ciências concernentes ao uso das TDIC na escola. A pesquisa foi efetivada junto a licenciandos das áreas de Ciências Biológicas e Física, no semestre 2011.2 e se caracteriza como Estudo de Caso. Subdividida nas etapas: conhecimentos prévios; planejamento de aula e análise de dados, utiliza questionários e planos de aula digitais como instrumentos de coleta de dados. Constatou-se que os licenciandos apresentam uma visão aplicacionista do uso das TDIC nas aulas de Ciências, com possibilidades de mudança nos casos em que se colocam a favor da construção do conhecimento a partir da reflexão.

\section{Introdução}

Na contemporaneidade do século XXI, é possível se integrar computadores, celulares, máquinas fotográficas, máquinas de vídeo, em um único dispositivo. Com a premissa de facilitar a vida do usuário, o mercado econômico direcionado para o setor das tecnologias digitais se incrementa, sobretudo pela inserção dos tablets e smartphones.

O comportamento humano diante do uso contínuo das tecnologias digitais da informação e comunicação (TDIC) vem se alterando. Nos espaços virtuais intensifica-se o desenvolvimento da cibercultura, por meio do crescimento do mundo globalizado, mobilidade (LIMA et al., 2011) e de possibilidades diversas de comunicação entre pessoas de diferentes culturas e costumes. A busca por respostas imediatas, o trabalho 
multitarefa, a atenção dividida são algumas das características que se apresentam. Neste contexto se encontram as Universidades, escolas, professores e alunos. No entanto, as possibilidades de espaços e de aprendizagens que a educação brasileira oferece ainda estão aquém do que é apresentado à sociedade em relação ao uso das TDIC.

Com um excesso de aulas expositivas, pouco interativas, colocando o aluno na situação de receptor do conhecimento, a escola ainda transfere a mesma metodologia e trabalhos tradicionais para o uso das TDIC. Diante de softwares sofisticados, de inúmeros endereços e comunidades virtuais, os alunos ainda desenvolvem o hábito da cópia e pouca reflexão. Constituem-se, assim, seres passivos diante do conhecimento. E como se situam os professores? Estão preparados para trabalhar pedagogicamente com essas ferramentas, contribuindo inclusive com inovações metodológicas (VALENTE; BUSTAMANTE, 2009).

Pesquisas sobre Formação de Professores revelam que os professores não se estão preparados para lecionar, especialmente quando necessitam integrar diferentes conhecimentos de forma interdisciplinar. Tardif (2002) ressalta que o modelo de formação de professores ainda hoje se baseia numa proposta aplicacionista do conhecimento, desconsiderando suas crenças e conhecimentos prévios. Lançados no mercado de trabalho, mostram-se despreparados para a atuação em sala de aula, desconhecem os papéis que precisam desempenhar. Valente (2002) e Almeida (2008) destacam ainda que os professores não estão conscientes das necessidades demandadas pela sociedade da informação, que apontam para um profissional criativo, autônomo e reflexivo.

Quando se trata do professor de Ciências a situação não é diferente. Com pouca autonomia intelectual, e, apoiado nos livros didáticos, se torna um mero transmissor de conteúdos baseando-se as concepções que desenvolvem a partir do senso comum, desconhece a evolução epistemológica do conhecimento científico, não é capaz de questionar o que lhe é imposto pelo currículo escolar (CARVALHO; GIL-PÉREZ, 2006). Rezende, Lopes e Egg (2004) revelam que os professores não compreendem a necessidade da integração de diferentes saberes na formulação dos conteúdos didáticos e procuram evitar o uso do laboratório de informática.

Pensar criticamente o uso da tecnologia digital, sua influência na escola e nas aulas de ciências é uma tarefa imprescindível. Considerando-se que as Tecnologias Digitais da Informação e Comunicação (TDIC) são instrumentos culturais, pois possibilitam a criação de novas linguagens e comportamentos, se faz premente o desenvolvimento de uma formação de professores que promova a integração pedagógica das tecnologias digitais ao currículo (ALMEIDA; ASSIS, 2010). Ao utilizar novas ferramentas informáticas em contextos educacionais, os licenciandos podem incrementar modificações metodológicas e serem incentivados a inovar suas práticas profissionais (CARVALHO; GIL-PÉREZ, 2006).

Para possibilitar o desenvolvimento de uma formação capaz de integrar saberes científicos aos tecnológicos digitais, é necessário promover situações didáticas que contemplem a utilização dos conhecimentos prévios dos licenciandos sobre o conceito de tecnologia digital (AUSUBEL; NOVAK; HANESIAN, 1980), bem como situações didáticas nas quais os licenciandos apliquem esses conhecimentos em suas práticas pedagógicas (CARVALHO; GIL-PÉREZ, 2006). 
Diante deste cenário, questiona-se: Como os licenciandos na área de Ciências pensam a utilização da tecnologia digital no contexto escolar? Sendo assim, o objetivo deste trabalho é analisar as relações estabelecidas entre os conhecimentos prévios e as propostas de ação pedagógica dos licenciandos na área de Ciências sobre o uso das TDIC em sala de aula.

\section{O uso das TDIC no Contexto da Formação do Professor de Ciências}

A discussão relacionada à integração da tecnologia ao contexto escolar, para alguns autores, extrapola a ideia do simples uso da tecnologia, seja ela digital ou não. A proposta de trabalhar com tecnologia é torná-la possível enquanto produto a ser desenvolvido na própria escola. O Movimento CTSA (Ciências, Tecnologia, Sociedade e Ambiente) justifica esse fato. Primeiramente, considera que os saberes científicos e tecnológicos levam a humanidade a um futuro melhor. Ressalta ainda que estes mesmos saberes devem ser orientados para a ação a partir da análise social, histórica, política e econômica. Sendo assim, o desafio da escola é superar o paradoxo de que, apesar das ciências não serem aceitas pelos alunos, a sociedade prestigia não só a ciência como também a tecnologia. Busca-se, nesse sentido, uma proposta que possibilite a alfabetização científica e tecnológica por meio da reorientação dos saberes ensinados, da superação das dificuldades dos professores em abstrair suas experiências tornando os saberes práticos menos discursivos e de mudanças na rotina das ações de professores e alunos impostas pela escola (RICARDO, 2007).

Para que o movimento CTSA faça parte da escola é necessário integrar a tecnologia ao currículo escolar. $O$ status que a tecnologia recebe é inferior àquele atribuído às ciências, considerando-a como uma aplicação científica, o que reflete em uma desconsideração de suas implicações sociais, econômicas e culturais no ambiente escolar. Sendo assim, percebe-se que os conteúdos científicos na escola são consolidados historicamente, ao passo que a tecnologia não é contemplada do ponto de vista curricular. $O$ que se faz é a utilização e valorização da tecnologia, enquanto ferramenta em prol de um distanciamento da ideia de tecnologia como um produto possível de ser construído por professores e alunos.

Ricardo (2007) ressalta que a tecnologia integra o "saber fazer", enquanto conhecimento sistematizado, às diferentes formas de ação relacionadas aos processos e produtos com o objetivo de solucionar problemas, transformando o ambiente natural e sócio-cultural. Seu ponto forte é o referencial metodológico que contempla a análise do objeto e da elaboração de projetos. Ao buscar essa integração, propõe que temas, problemas e interesses sejam retirados da realidade cotidiana, para que os saberes disciplinares, denominados pelo autor como técnico-científicos, sejam utilizados para a construção de respostas, modelos e esquemas.

Ribeiro et al. (2008), diante das necessidades de reverter o cenário de fragilidades do ensino médio brasileiro, nas áreas de ciências e matemática, questionam a necessidade de promover uma discussão de questões e estratégias, relacionadas à articulação da realização de práticas e do uso de laboratórios de experimentação científica e informática educativa, a fim de integrá-los, de forma mais consubstancial, ao currículo, adotando-se novos olhares pedagógicos.

Para contemplar os aspectos na Formação do Professor de Ciências é necessário fazer com que o licenciando vivencie situações com essas características, que seja 
também um produtor de conhecimento a partir dos problemas captados pelo mundo exterior e solucionados com a fundamentação científica necessária para este fim. Ao trabalhar no contexto das TDIC, esse objetivo é alcançado quando são possibilitados recursos que permitam a exploração, a investigação e a descoberta. De acordo com Baranauskas et al. (1999) os sistemas tecnológicos a serem utilizados devem ser análogos aos sistemas físicos. Sem ensinar ou instruir, permitem que o aprendiz, seja ele aluno ou professor, atue como cientista aplicando princípios a um sistema de experimentação. Ambientes que permitem o desenvolvimento de simulações de situações científicas, o desenvolvimento de modelos, o desenvolvimento de programas básicos e pequenos softwares de autoria são exemplos de ferramentas que podem auxiliar a assimilação, de forma reflexiva e crítica, de conceitos científicos integrados aos conhecimentos tecnológicos.

Baranauskas et al. (1999) ressaltam ainda que o trabalho dentro dessa perspectiva construcionista de aprendizagem, tornam evidentes alguns aspectos relevantes. A aprendizagem se torna efetiva por meio da construção do conhecimento, da liberdade de ação, da reflexão a partir dos erros e dos acertos cometidos no processo. Os feedbacks enviados pelo sistema em uso, considerados importantes para o processo de aprendizagem, são gerados como função de escolhas e de ações do aprendiz dentro do sistema.

É importante ressaltar que a mediação do professor nesse processo é fundamental. Por meio do diálogo que estabelece com o aprendiz, é que novas ideias podem surgir para que a resolução do problema seja possibilitada. A compreensão sobre esta mediação, no entanto, não surge da simples prática ou compreensão teórica, mas da integração de ambas. Por isso, compreende-se que o uso das TDIC no contexto da formação do professor de ciências deve englobar o conhecimento da técnica, da tecnologia e de seus diferentes usos, sejam eles científicos ou pedagógicos inseridos no contexto curricular.

Para que a aprendizagem do licenciando nesse processo de integração se torne significativa é necessário que os novos conhecimentos sejam ancorados aos conhecimentos já existentes em suas estruturas cognitivas de forma substantiva e nãoarbitrária (AUSUBEL; NOVAK; HANESIAN, 1980). Sendo assim, compreender quais são os conhecimentos prévios dos licenciandos relacionados às TDIC possibilita maior esclarecimento de como iniciar o processo de formação a partir de ações contextualizadas capazes de, pouco a pouco, construir uma cultura digital a ser incorporada também na prática de sala de aula.

De acordo com Carvalho e Gil-Pérez (2006), a formação do professor de Ciências precisa contemplar diferentes aspectos relacionados à integração dos saberes científicos aos saberes pedagógicos e curriculares. A preparação das atividades e estratégias pedagógicas concernentes às sessões didáticas é fundamental. O licenciando deve evitar o uso do senso comum em seu fazer docente, procurando vincular saberes adquiridos em sua experiência de vida aos seus saberes científicos previamente consolidados. Em Ciências, é importante que o professor, de forma reflexiva, saiba compreender a importância da identificação prévia das ideias dos alunos para desenvolver atividades que introduzam novos conceitos de forma significativa e colaborativa, além de inseri-los em diferentes contextos, dentre eles o digital. 


\section{Metodologia}

A pesquisa apresenta caráter qualitativo e se baseia nos pressupostos teóricos do Estudo de Caso, principalmente no momento do planejamento, do emprego de técnicas de coleta e de abordagens de análise de dados que utilizam várias fontes de evidência, incluindo as proposições teóricas que norteiam a pesquisa (YIN, 2005). Apresenta-se, portanto, parte dos resultados obtidos em pesquisa de Doutorado em andamento, vinculada ao Programa de Pós-Graduação em Educação Brasileira da Universidade Federal do Ceará.

A unidade de análise da pesquisa é composta por sete estudantes dos cursos de Licenciatura em Ciências Biológicas e Licenciatura em Física da Universidade Federal do Ceará, em fase de finalização da graduação, $7^{\circ}$ e $8^{\circ}$ semestres, no contexto da disciplina Informática Aplicada ao Ensino de Ciências (IAEC), oferecida pelo Departamento de Computação e realizada durante o semestre letivo 2011.2.

A pesquisa se subdivide em três etapas: conhecimentos prévios, planejamento de aula e análise dos dados. Na primeira etapa, buscam-se conhecer o perfil sócioeconômico e cultural dos estudantes, seus conhecimentos prévios sobre tecnologia e tecnologia digital. Na segunda etapa, busca-se compreender de que forma os estudantes planejam aulas que contemplem o ensino de ciências vinculado ao uso da tecnologia digital. Na terceira etapa, busca-se comparar os resultados obtidos nas duas primeiras etapas, observando-se as semelhanças e discrepâncias entre o que eles pensam sobre tecnologia digital e o que conseguem planejar em termos de ação pedagógica.

Os instrumentos de coleta e análise de dados se baseiam em ferramentas digitais. Para a primeira etapa são utilizados questionários preparados em formulários digitais e disponibilizados aos licenciandos em endereço específico na internet. Na segunda etapa, é disponibilizado um modelo de plano de aula digital, compartilhado pela professora da disciplina IAEC com cada aluno individualmente por meio de ferramenta virtual. Na terceira etapa, os dados coletados são armazenados e organizados em planilha eletrônica, subdivididos pelas etapas às quais pertencem, para que, posteriormente, sejam comparados entre si à luz do referencial teórico apresentado, por meio de uma triangulação metodológica (STAKE, 1998).

São apresentados neste trabalho os principais resultados obtidos a partir da coleta de dados e uma breve discussão resultante da análise dos dados.

\section{Resultados e Discussão}

Os sete licenciandos participantes da pesquisa apresentam faixa etária média de 22 anos, sendo cinco alunos do curso de Licenciatura em Ciências Biológicas e dois alunos do curso de Licenciatura em Física. Apenas um aluno não tem renda própria, os demais atuam como bolsistas da Universidade ou atuam como professores do Ensino Fundamental II, mesmo não tendo terminado a formação inicial. Afirmam utilizar o computador e a internet diariamente principalmente para realizar trabalhos acadêmicos e para entretenimento. Apesar de fazerem uso com freqüência do correio eletrônico, e de participar de redes sociais, não conhecem nenhum software específico para trabalhar com Biologia ou Física do ponto de vista científico, nem do ponto de vista do ensino de Ciências. A única exceção ocorreu com um aluno da Física que teve contato com softwares matemáticos para o desenvolvimento de simulações. Apesar de a Universidade disponibilizar computadores e internet a todos os departamentos, cinco 
alunos preferem utilizar suas ferramentas digitais particulares, alegando maior comodidade. Para dois alunos, o uso na Universidade é melhor por ser gratuito e apresentar uma internet mais veloz.

Ao definirem o conceito de "tecnologia", o termo "ferramenta" ou "instrumento" é utilizado em $18 \%$ das definições; o termo "técnica" apresenta-se em 15\% delas; ao passo que os termos "estudo", "conceito", "modelo" e "científico", são menos frequentemente lembrados, constando em apenas $4 \%$ das definições apresentadas. É importante frisar que em todas as definições o termo "tecnologia" vincula-se à ideia de praticidade, de uso que facilita, auxilia ou otimiza a vida humana ou em sociedade. Em duas ocasiões, no entanto, o termo "criação" também se apresenta como uma associação ao temo "tecnologia".

A ideia que os licenciandos apresentam sobre o conceito de tecnologia baseia-se em uma visão aplicacionista, valorizando-a enquanto ferramenta, sem a consideração de suas implicações na sociedade. Para Ricardo (2007) esse tipo de valorização, construto do que se desenvolve na escola, promove um distanciamento da ideia de tecnologia como um produto possível de ser construído por professores e por alunos. O objetivo da utilização da tecnologia deveria ser a busca pela solução de problemas que transformem o ambiente natural e sócio-cultural. Nesse sentido, recomenda-se que a Formação do Professor de Ciências promova situações nas quais os licenciandos se tornem produtores de conhecimento a partir de problemas captados pelo mundo exterior e solucionados com a fundamentação científica para este fim.

Ao definirem "tecnologia digital" os conceitos de "ferramenta" e de "técnica" permanecem presentes em $38 \%$ das respostas. No entanto, relacionam em $23 \%$ das definições, ao conceito de "mídia digital", e, em $15 \%$ ao conceito de "computador". Apenas $8 \%$ das respostas vinculam "tecnologia digital" ao conceito de "linguagem digital" ou "linguagem binária". Também em $8 \%$ dos casos os licenciandos estabelecem uma relação entre tecnologia digital ao uso da energia elétrica.

As ideias que os licenciandos trazem sobre tecnologia digital continuam vinculadas a uma visão aplicacionista do conhecimento. No entanto, por apresentar o aspecto digital, relacionam o conceito ao uso das mídias e do computador. É importante ressaltar que a tecnologia digital pode existir independente do uso do computador. Os relógios digitais, as calculadoras de bolso, por exemplo, são tecnologias digitais, mas não precisam de um computador para ser utilizados; fazem uso, porém, de uma linguagem específica, a linguagem binária. Detecta-se neste momento uma construção conceitual que pode estar equivocada e precisa ser discutida com os licenciandos para a ampliação da visão do que é tecnologia digital e de que forma pode ser utilizada nas aulas de Ciências.

Em relação aos planos de aula desenvolvidos pelos licenciandos, são analisados a estrutura das aulas, o tipo de conteúdo abordado em cada parte desta estrutura, as ferramentas comumente planejadas para uso em sala de aula, e, das ferramentas digitais, todas as que são citadas. Em geral, os licenciandos subdividem suas aulas em três momentos: inicial, desenvolvimento e conclusão. No momento inicial, utilizam Questionamentos para proporcionar junto aos alunos um momento de Discussão: "Antes de começar a passar conteúdos, perguntarei aos alunos como nós nascemos e por que somos do jeito que somos (tempestade de ideias)". No momento do desenvolvimento, os licenciandos optam por trabalhar com a Apresentação de conceitos, 
com a Explicação de teorias, novamente com Questionamentos que se mesclam às estratégias de ensino, bem como, a Aplicação dos conhecimentos apresentados aos alunos por meio de exercícios e atividades: "Em cima do que foi debatido na atividade anterior relacionar/apresentar o conteúdo previsto (vídeo ou aula expositiva)"; "aplicar através de jogos digitais (duplas), em que trabalhe o conteúdo, no laboratório de Informática". No momento da conclusão da aula, recorrem à Apresentação e Explicação do conteúdo em questão, além de trabalhar com Resolução de problemas como uma forma de avaliação do conhecimento abordado: "Por último, os alunos resolverão os exercícios do livro didático".

O tipo de conteúdo mais abordado nas aulas se baseia na Apresentação de informações (38\%). A segunda maior preocupação dos licenciandos é com o momento final da aula, ocasião em que deverão, segundo eles, avaliar a aprendizagem dos alunos (19\%). A Explicação dos conteúdos teóricos, os Questionamentos e Discussões, bem como a Aplicação do conhecimento abordado em diferentes situações não são interesse geral para todos os licenciandos.

As ferramentas comumente utilizadas se baseiam na tecnologia digital (40\%) e na oralidade (37\%). No primeiro caso, os licenciandos preferem sua utilização nos momentos de Apresentação dos temas científicos; outros momentos como Discussão, Explicação e Aplicação do conteúdo trabalhado também são citadas. No segundo caso, não existe uma concentração para momentos específicos da aula. A oralidade é utilizada em praticamente todos eles: Questionamento, Discussão, Apresentação, Explicação e Resolução de problemas; só não é citada no momento da Aplicação do conhecimento. Outras ferramentas como o quadro branco (9\%), o livro didático $(6 \%)$, o trabalho em grupo (6\%), o jornal e a revista como fonte de dados $(3 \%)$ são citados com menor ênfase. Geralmente são utilizados nos momentos de Apresentação, Discussão, Explicação e Resolução de problemas.

Em relação ao uso das ferramentas digitais, os licenciandos destacam o vídeo, a simulação, a animação, o jogo educativo, a exposição de conteúdos e a ilustração como estratégias nas quais necessitam não só do computador, como também do projetor multimídia e de softwares específicos para apresentação de informações. É importante destacar, no entanto, que a utilização de vídeos foi a estratégia mais citada pelos licenciandos (58\%); as demais alcançaram, cada uma, apenas $8 \%$ das indicações.

De acordo com Almeida e Silva (2011) as tecnologias digitais passaram a fazer parte da cultura atual, penetrando o âmbito da educação, embora nem sempre vivenciada em sua plenitude. As ferramentas mais utilizadas são os jogos eletrônicos, as ferramentas da Web 2.0, as mídias sociais e os dispositivos móveis como celulares e computadores portáteis. $\mathrm{O}$ que se percebe a partir dos resultados da pesquisa é que os licenciandos, sujeitos da pesquisa, apesar de utilizar ferramentas digitais mais atuais para as tarefas pessoais e acadêmicas, no momento de pensar na atuação em sala de aula, utilizam as ferramentas digitais para auxiliar na apresentação e na aplicação do conteúdo, o que justifica o grande número de propostas com utilização de vídeos, bem como a necessidade de uso do projetor multimídia. A postura dos licenciandos difere, portanto, daquela apresentada por Almeida e Silva (2011), o que pode caracterizar, dentro da formação docente, um distanciamento do uso das TDIC no contexto da prática docente. 
Para Basso (2009), as estratégias utilizadas pela escola para o uso dos novos dispositivos digitais continuam sendo as antigas estratégias pedagógicas enquadrando o uso das mídias à lógica historicamente instituída. Os professores trabalham em sala de aula fazendo uso da metodologia convencional utilizando-se das tecnologias "da moda" que trazem para o imaginário social a ideia de inovação. Para os licenciandos da pesquisa este tipo de prática é evidente. As estratégias mais comumente disponíveis são aquelas na qual o licenciando apresenta o conteúdo por meio do uso de vídeos na própria sala de aula. Em ocasiões nas quais os licenciandos pensam o uso do laboratório de informática, o objetivo é utilizar softwares de simulação e jogos eletrônicos que permitem a visualização dos fenômenos científicos: "através de um experimento virtual com a representação de um sistema planetário, fazer com que os alunos visualizem os conceitos e as leis de Kepler expostos na aula teórica em ação. Se possível, cada aluno deve participar do experimento individualmente". A maneira como abordarão essa visualização, promovendo reflexões, levantamento de hipóteses e elaborações lógicas a partir de contra-exemplos, como destacam Carvalho e Gil-Pérez (2006) não são explicitadas.

Ao comparar os resultados obtidos com a aplicação do questionário e com a aplicação dos planos de aula é perceptível que os licenciandos pensam o uso da tecnologia digital restrito à utilização de vídeos, animações e imagens para a apresentação de conteúdos como um repasse de informações. As ferramentas digitais possuem a função de auxiliar o professor em seu processo de ensino, diante de uma visão instrucionista, na qual o aluno recebe as informações de forma passiva ao assistir as apresentações do professor. A tecnologia digital é de fato idealizada como um instrumento para o repasse de informações; adquire não só uma visão aplicacionista, mas também uma ação exclusiva do professor, diante da não interação entre aluno e tecnologia digital.

\section{Considerações Finais}

Considerando-se os sujeitos pesquisados como estudantes dos últimos anos da graduação da universidade, percebe-se que a articulação da tecnologia digital com os diferentes saberes necessários para se tornar um professor preparado para o mercado de trabalho não foi concretizada. Uma única disciplina, como o caso da IAEC, não é suficiente para produzir uma mudança cultural dos licenciandos, frente ao uso adequado das tecnologias digitais na escola. Para Valente e Bustamante (2009) é necessário que o professor compreenda que, pedagogicamente, o computador pode contribuir para representar o conhecimento e permitir sua reconstrução, em busca da inovação de ideias, valores e saberes. Sendo assim, é preciso que o licenciando se torne capaz de descrever soluções para problemas propostos, refletir sobre os resultados obtidos, depurar ideias em busca de novos conhecimentos e, a partir de então, desenvolver novas estratégias para o problema proposto. O que falta é uma Formação de Professores que integre esses aspectos em sua estrutura curricular, incorporando o uso das TDIC em todas as disciplinas que compõem a licenciatura.

Ainda assim, é possível perceber que, em casos isolados, existe uma preocupação com o desenvolvimento do pensamento reflexivo do aluno a partir da utilização da tecnologia digital em situações de simulação e jogos eletrônicos. Em outros casos, o pensamento dos licenciandos está também vinculado à ideia de criação do conhecimento e de novas tecnologias. Compreende-se, com isso, que é possível a 
inserção de discussões e ações que permitam aos licenciandos a construção de novos conhecimentos e escolha de diferentes ferramentas digitais a serem incorporadas e utilizadas em seus planejamentos de aula. Este é, portanto, o próximo passo de investigação a ser trabalhado na pesquisa em andamento.

\section{Referências}

ALMEIDA, M. E. B. de. Mapeando percepções de docentes no CHIC para análise da prática pedagógica. In: OKADA, A. (org.). Cartografia Cognitiva: Mapas do conhecimento para pesquisa, aprendizagem e formação docente. Cuiabá: KCM, 2008, p. 325-338.

ALMEIDA, M. E. B. de; ASSIS, M. P. de. Web Currículo: Integração das Tecnologias na Educação. In: Encontro Nacional de Didática e Prática de Ensino, 15., 2010, Belo Horizonte. Anais do XV Encontro Nacional de Didática e Prática de Ensino. Belo Horizonte, 2010. p. 1-33.

ALMEIDA, M. E. B. de; SILVA, M. da G. M. da. Currículo, tecnologia e cultura digital: espaços e tempos de web currículo. Revista e-curriculum, São Paulo, v.7, n.1, abril, 2011. Disponível em: <http://revistas.pucsp.br/index.php/curriculum>. Acesso em: 15 jun. 2012.

AUSUBEL, D. P; NOVAK, J. D.; HANESIAN, H. Psicologia Educacional. Rio de Janeiro: Interamericana, 1980.

BARANAUSKAS, M. C. C.; ROCHA, H. V. da; MARTINS, M. C.; D’ABREU, J. V. V. Uma Taxonomia para Ambientes de Aprendizado baseados no Computador. In: VALENTE, J. A. (org.). O computador na sociedade do conhecimento. Campinas: Unicamp/NIED, p. 49-68, 1999.

BASSO, M. A. J. Currículo e Web 2.0: Argumentos possíveis a uma diferenciação em educação digital. Revista e-curriculum, São Paulo, v. 4, n. 2, jun., 2009. Disponível em: 〈http://www.pucsp.br/ecurriculum>. Acesso em: 20 jun. 2012.

CARVAlho, A. M. P. de; GIL-PÉREZ, D. Formação de Professores de Ciências: tendências e inovações. São Paulo: Cortez, 2006.

LIMA, L. de; BARROS FILHO, E. M. de; RIBEIRO, J. W.; ANDRADE, R. M. de C.; VIANA, W.; LEITE JÚNIOR, A. J. M. Guidelines for the development and Use of MLearning Applications in Mathematics. IEEE Multidisciplinary Engineering Education Magazine, v. 6, n. 2, p. 1-12, june, 2011.

REZENDE F.; LOPES, A M. de A.; EGG, J. M. Identificação de problemas do Currículo, do Ensino e da Aprendizagem de Física e de Matemática a partir do discurso de professores. Ciência \& Educação, v. 10, n. 2, p. 185-196, 2004.

RICARDO, E. C. Educação CTSA: Obstáculos e possibilidades para sua implementação no contexto escolar. Ciência \& Ensino, v. 1, n. especial, novembro, 2007.

RIBEIRO, J. W.; VALENTE, J. A.; FREITAS, D. B. de; MARTINS, D. G.; SANTOS, M. J. C. dos. Integração de Atividades de Educação em Ciências Utilizando TIC: Uma Experiência na Formação Continuada de Educadores do Ensino Médio. In: Seminário 
Web Currículo PUC-SP, 1., 2008, São Paulo. Anais do I Seminário Web Currículo PUC-SP, São Paulo, 2008. CD ROM.

STAKE, R. E. Investigación com estúdio de casos. Madrid: Morata, 1998.

TARDIF, M. Saberes docentes e formação profissional. Petrópolis, RJ: Vozes, 2002.

VALENTE, J. A. A Espiral da Aprendizagem e as Tecnologias da Informação e Comunicação: repensando conceitos. In: JOLY, M. C. A Tecnologia no Ensino: implicações para a aprendizagem. São Paulo: Casa do Psicólogo Editora, p. 15-37, 2002.

VALENTE, J. A.; BUSTAMANTE, S. B. V. (orgs.). Educação a distância: prática e formação do profissional reflexivo. São Paulo: Avercamp, 2009.

YIN, R. K. Estudo de Caso: planejamento e métodos. Porto Alegre: Bookman, 2005. 